\title{
The Tegmental Pedunculopontine Nucleus: A Brain-Stem Output of the Limbic System Critical for the Conditioned Place Preferences Produced by Morphine and Amphetamine
}

\author{
Antoine Bechara and Derek van der Kooy \\ Neurobiology Research Group, Department of Anatomy, Faculty of Medicine, University of Toronto, Toronto, Ontario \\ Canada, M5S $1 \mathrm{~A} 8$
}

The potent reinforcing properties of psychoactive drugs have been attributed to the activation of motivational processes localized to the limbic system. We investigated the role of 2 specific outputs of the forebrain limbic system, the tegmental pedunculopontine nucleus (TPP) and the periacqueductal gray (PAG) of the pons-midbrain, in the positive motivational effects of morphine and amphetamine. We now report that the TPP, but not the PAG nor other nearby regions, is a critical site in the neural system subserving the rewarding effects of both opiates and stimulants. Bilateral ibotenic acid lesions of the TPP blocked the positive reinforcing effects of both morphine and amphetamine in naive rats as measured in a conditioned place preference paradigm. However, TPP lesioned animals were still capable of acquiring a conditioned place preference to an environment paired with the peripheral opiate antagonist methylnaltrexone. This suggested that TPP lesions did not cause nonspecific deficits in the basic learning mechanisms underlying conditioned place preferences. Furthermore, while the TPP was critical for the acquisition of a conditioned preference to an environment paired with morphine in naive rats, rats that had acquired a morphine conditioned place preference prior to the lesions were capable of retaining and demonstrating these place preferences after lesions of the TPP. This again demonstrates that TPP lesions are producing an unconditioned deficit in motivation rather than a deficit in learning or memory. Finally, direct comparisons of the place preference data of individual animals with their correspondent TPP lesion sites Indicated that the most effective lesions overlapped to a greater degree TPP perikarya with descending, rather than ascending, axons. This suggests that motivational information generated by drug stimuli acting at "upstream" neural structures flows in a descending direction through the TPP region of the brain stem.

These results suggest that opiates and stimulants must ultimately activate a single brain-stem substrate in order to have a positive motivational impact. It is hypothesized that the neural circuits mediating the rewarding effects of drug

\footnotetext{
Received Mar. 6, 1989; accepted Apr, 10, 1989.

Supported by the Medical Research Council of Canada. Thanks to Drs. Gerard M. Martin and Mark Katz for their valuable help, Dr. A. Merz for the gift of methylnaltrexone, and Ms. Adora Pridgar for her excellent technical assistance.

Correspondence should be addressed to A. Bechara, Department of Anatomy, Medical Sciences Building, University of Toronto, Toronto, Ontario, Canada M5S 1 A8.
}

Copyright (C) 1989 Society for Neuroscience $0270-6474 / 89 / 103400-10 \$ 02.00 / 0$ stimuli acting at forebrain sites exit the limbic system in the TPP region of the brain stem, where motivation may ultimately influence or be isomorphic with the elicitation of motor responses subserving approach and exploration.

The potent positive-reinforcing effects produced by systemic administrations of opiates (such as heroin and morphine) and stimulants (such as amphetamine and cocaine) have been attributed to the activation of endogenous appetitive motivational systems (Stewart et al., 1984) localized to the limbic system in the brain. Indeed, the anatomical concept of a limbic system was originally formulated as a neural substrate for motivation and emotion (Papez, 1937; MacLean, 1949). However, this concept did not explain how neurons in the limbic system were related to somatomotor or visceromotor (neuroendocrine and autonomic) neural systems that control the expression and perception of emotional behavior.

Although the exact definition of what constitutes the limbic system appears to have been in constant flux (Swanson, 1983), there seems to be general agreement that many components of the limbic system of the forebrain send fibers through the medial forebrain bundlc. The medial forebrain bundle comprises as many as 50 independent descending and ascending pathways connecting the forebrain to the midbrain and brain stem (Nieuwenhuys et al., 1982; Veening et al., 1982). Thus, the search for the neural processes underlying positive reinforcement has most often focused on pathways traveling through the medial forebrain bundle. Studies of electrical brain self-stimulation have identified the medial forebrain bundle as a prime substrate for reward (Olds and Olds, 1965; Rolls, 1975; Wise and Bozarth, 1984), and the neurons directly stimulated by the electrode are apparently myelinated, fast-conducting, and descending neurons that have short refractory periods (Shizgal et al., 1980; Yeomans, 1989).

Several lines of evidence have also indicated the importance of the medial forebrain bundle in mediating the rewarding effects derived from the intracerebral microinjection of various psychoactive drugs. Rats show preferences for environments associated with the intracerebral microinjection of opiates into the ventral tegmental area, nucleus accumbens, lateral hypothalamus, and periacqueductal gray (Phillips and LePiane, 1980, 1982; van der Kooy et al., 1982). However, the microinjection of similar doses of opiates into the caudate putamen, amygdala, and nucleus ambiguus is ineffective in producing conditioned place preferences (van der Kooy ct al., 1982), despitc the relatively high concentrations of opiate receptors in these regions 
(Atweh and Kuhar, 1977a, b). Furthermore, rats will self-administer opiates into the ventral tegmental area (Bozarth and Wise, 1981), lateral hypothalamus (Olds, 1979; Olds and Williams, 1980), and nucleus accumbens (Olds, 1982; Goeders et al., 1984) but will not self-administer opiates into the caudate nucleus (Bozarth and Wise, 1981). Similar to the results with opioids, rats show conditioned preference for places associated with the microinjection of amphctaminc into the nucleus accumbens but not into the striatum (Carr and White, 1986). Furthermore, rats self-administer amphetamine into the nucleus accumbens, while intrastriatal amphetamine self-administration is rare (Hoebel et al., 1982). Although most if not all of these brain regions tested for the rewarding effects of microinjected opioids and stimulants eventually influence fibers traveling in the medial forebrain bundle, only brain sites within or directly adjacent to the medial forebrain bundle were identified as positive reward sites. Thus, the medial forebrain bundle may serve as a primary substrate for the rewards derived from both electrical brain stimulation and psychoactive drugs.

The medial forebrain bundle projects down to a wide swath of midbrain and rostral pons referred to as the "limbic midbrain" by Nauta (Nauta, 1958; Swanson et al., 1984). The majority of descending medial forebrain bundle projections terminate in the midbrain and pons, although a small minority of medial forebrain bundle fibers do reach the spinal cord (Swanson and Kuypers, 1980). Several lines of evidence have pointed to the importance of structures caudal to the medial forebrain bundle stimulation sites in the mediation of the reward derived from the electrical self-stimulation of neurons in the medial forebrain bundle. Lateral or posterior hypothalamic self-stimulation rate is decreased by small lesions in or near the medial forebrain bundle both rostral (in the preoptic area) and caudal (near the interpeduncular nucleus of the midbrain) to the stimulating electrode (Boyd and Gardner, 1967; Olds and Olds, 1969). However, a caudal lesion produces the greater decrease in rate, and in contrast to a rostral lesion there is no partial recovery of rate over the few days following the lesion. Furthermore, the occurrence of lateral hypothalamic self-stimulation in rats after removal of almost the entire telencephalon (Huston and Borbely, 1973) suggests that much of the forebrain is probably not essential for this reward. Taken together, these experiments suggest that the brain regions that are caudal to the medial forebrain bundle self-stimulation sites may be critical in controlling whether self-stimulation occurs. Unfortunately, there are some limitations in studies attempting to demonstrate the direct "downstream" nature of the brain-stem nuclei subserving medial forcbrain bundle reward. First, the survival rate of rats with large electrolytic lesions within the midbrain and brain stem is relatively poor. Second, electrolytic lesions are generally confounded by the fact that these lesions do not only destroy neuronal cell bodies, but also damage the axons en route to other brain structures. However, it is now possible to obtain good survival with brain-stem lesions that selectively destroy cell bodies while sparing fibers of passage by using chemical excitotoxins such as ibotenic acid (Coyle and Schwarcz, 1983).

Given the primary role of the medial forebrain bundle in the reward derived from both electrical brain stimulation and psychoactive drugs, as well as the putative importance of caudal structures in the control of these positive-reinforcing effects, we hypothesized that a selective removal of neuronal cell bodies (using ibotenic acid lesions) within regions of the limbic midbrain and pons that receive medial forebrain bundle outputs might abolish the rewarding effects elicited by psychoactive drugs. Therefore, we examined the effects of bilateral ibotenic acid lesions of 2 sites within the limbic midbrain and pons-the tegmental pedunculopontine nucleus (TPP) and the periacqueductal gray (PAG)-on the rewarding effects of morphine in opiate naive rats. We now report that lesions of the TPP, but not of the PAG, region abolished the preferences for environmonts conditioned to the rewarding effects of even high doses of morphine in drug naive rats. These lesions were also effective in blocking the acquisition of amphetamine-conditioned place preferences. We suggest that TPP lesions cause a specific deficit in the unconditioned rewarding effects of these psychoactive drugs.

\section{Materials and Methods}

Subjects. All animals used in these experiments were adult male Wistar rats (Charles River) weighing 350-450 gm. Subjects were housed individually in suspended gray wire cages in a room kept at a temperature of $22^{\circ} \mathrm{C}$ and lit between 0900 to 2100 . Purina rat chow was available ad lib throughout the experiments. Water was continuously available.

Surgery. Different groups of rats were anesthetized with $0.8 \mathrm{ml} / \mathrm{kg}$ doses of Somnital. Each of the rats was placed in a stereotaxic apparatus, a scalp incision was made, and 2 small holes were drilled in the skull to allow passage of a needle. Each rat was either bilaterally injected with $0.2 \mu \mathrm{l}$ of a $4 \%$ ibotenic acid solution via a $1 \mu \mathrm{l}$ Hamilton microsyringe over 25 min (lesion groups) or with physiological saline (sham groups). The needle was left in place for $5 \mathrm{~min}$ following the infusions. The injection coordinates as taken from the atlas of Paxinos and Watson (1982) (with the mouthbar set at $-3.3 \mathrm{~mm}$ below the interaural line) were AP $-7.8 \mathrm{~mm}$ posterior to bregma, $\mathrm{L} \pm 1.6 \mathrm{~mm}$ lateral to the midline, and DV $-5.8 \mathrm{~mm}$ below the dura for the TPP, and the PAG coordinates were $\mathrm{AP}-7.8 \mathrm{~mm}$ posterior to bregma, $\mathrm{L} \pm 0.8 \mathrm{~mm}$ lateral to the midline, and DV $-5.5 \mathrm{~mm}$ below the dura. The PAG lesions were designed to be approximately the same size (using the same volume of ibotenic acid) and at the same rostrocaudal level as the TPP lesions. At least 2 weeks were allowed for recovery from surgery before any experiments were begun. During the recovery period each rat was handled for a few minutes on each of several days.

Histology. At the end of the behavioral experiments, all the operated rats were deeply anesthetized with Somnital and perfused through the heart with isotonic saline followed by $10 \%$ formalin. The brains were removed and postfixed in $15 \%$ sucrose, and then $32 \mu \mathrm{m}$ cryostat sections were cut. Sections were mounted on gelatin-coated slides and stained with cresyl violet in order to verify the placement and extent of the lesions. Sections were examined and photographed in bright-field microscopy.

Place conditioning. The place-conditioning procedures were identical to those previously described (Mucha et al., 1982). Conditioning took place in 1 of 2 boxes that differed in color, texture, and smell. One had black walls and a black Plexiglas floor that was wiped with a $2 \%$ acetic acid solution just prior to placing each rat inside it. The other box had white walls and a wood chip floor that gave off a slight smell of wood. Each rat received 4 drug injections spaced equally over $8 \mathrm{~d}$ and was immediately confined after each drug injection to a distinct environment for $30 \mathrm{~min}$. On the 4 alternating days when no drug injection was given, each rat was injected with saline vehicle and confined for $30 \mathrm{~min}$ to the other separate and different distinctive environment. Order of injections and drug-paired environment were counterbalanced within groups. On day 9 , rats were selected at random so that the conditioning schedule was unknown to the experimenter. Each uninjected rat was then tested by recording the amount of time the rat spent in each of the 2 previously paired distinctive environments when given a $10 \mathrm{~min}$ period to explore both environments freely. During testing, the experimenter was blind as to which side of the box had been paired with a drug during training. The 2 environments of the test apparatus were separated by a neutral gray zone. For scoring purposes, the rat was defined as being in a given compartment when both forepaws were located in that compartment. The preference an animal showed for the previously drug-paired environment over the saline vehicle-paired environment was taken as a measure of drug reward (Mucha et al., 1982). This "unbiased" place conditioning method controls for possible interactions between an unconditioned side preference and various nonreinforcing effects of the 
drug (van der Kooy, 1987; Carr et al., 1989). Furthermore, this method of place conditioning, which balances the baseline preferences for the 2 compartments of the place-conditioning apparatus, has repeatedly been shown to yield equal preferences for both environments when nondrug-conditioned animals are allowed to explore both environments freely (Mucha et al., 1982; Mucha and Iverson, 1984; Bechara and van der Kooy, 1987, 1988)

A substantial body of research using the place-conditioning paradigm has accumulated over the past few years and confirms that this paradigm can serve as a valid and reliable measure of drug reward (van der Kooy, 1987; Carr et al., 1989). Challenges to this validity (Swerdlow and Koob, 1984; Heinrichs and Martinez, 1986; Scoles and Siegel, 1986) have been based largely on procedural variations, which do not typify conditioned place-preference studies in general (Carr et al., 1988, 1989) nor the paradigm employed in the present study in particular.

Morphine-conditioned place preferences after TPP or PAG lesions. The effects of lesioning different sites within the limbic pons and midbrain (the TPP and PAG) were measured by morphine-conditioned place preferences in 4 separate groups of drug and experiment naive rats. Two experimental groups received bilateral ibotenic acid lesions of either the TPP or PAG (TPP lesion, $n=8$; PAG lesion, $n=8$ ). The 2 remaining groups served as sham controls and received bilateral saline vehicle injections instead of ibotenic acid into either the TPP or PAG (TPP sham, $n=13$; PAG sham, $n=7$ ). Following recovery, all rats received place conditioning as described above with morphine $(1 \mathrm{mg} / \mathrm{kg}$, s.c.).

Dose-response analysis of morphine-conditioned place preferences after TPP lesions. From separate groups of TPP sham and ibotenic acidlesioned rats, we constructed a dose-response curve showing the effects of the lesions on the rewarding properties of several doses of morphine $(1,5$, and $10 \mathrm{mg} / \mathrm{kg}$, s.c.) measured in the place-conditioning paradigm. Prior to surgery all rats were drug and experiment naive. Three groups received bilateral ibotenic acid injections into the TPP. Following recovery, each group was place conditioned with only one dose of morphine (lesion $1 \mathrm{mg} / \mathrm{kg}, n=14$; lesion $5 \mathrm{mg} / \mathrm{kg}, n=8$; lesion $10 \mathrm{mg} / \mathrm{kg}$, $n=5$ ). Three other groups received sham instead of ibotenic acid lesions and were place conditioned with morphine in an identical manner to the lesion groups (sham $1 \mathrm{mg} / \mathrm{kg}, n=17$; sham $5 \mathrm{mg} / \mathrm{kg}, n=9$; sham $10 \mathrm{mg} / \mathrm{kg}, n=9$ ). All rats remained drug and experiment naive after surgery except for the sham and lesioned groups place conditioned with $5 \mathrm{mg} / \mathrm{kg}$ doses of morphine. These rats were subjects in a drug-discrimination experiment (Martin et al., 1987), in which they received 10 injections of $5 \mathrm{mg} / \mathrm{kg}$ morphine over a $20 \mathrm{~d}$ period that ended 1 week prior to the start of the place-conditioning experiment. It is worth mentioning that the place conditioning of the sham and lesion groups injected with $5 \mathrm{mg} / \mathrm{kg}$ of morphine was carried out by 2 separate experimenters blind to the conditions of the study. The type of the lesion was unknown to the experimenter carrying out the conditioning phase. The type of the lesion as well as the drug-paired side were unknown to the other experimenter carrying out the test phase.

Place preferences conditioned by amphetamine and methylnaltrexone after TPP lesions. In light of the evidence that TPP lesions abolished the positive motivational effects produced by opiates, we first asked whether the TPP region is involved in the positive-reinforcing properties of another psychoactive drug stimulus such as amphetamine. This experiment employed 2 separate groups of sham $(n=8)$ and lesioned rats $(n=8)$ that were drug and experiment naive. All rats were place conditioncd with amphetamine sulfate $(1 \mathrm{mg} / \mathrm{kg}$, s.c.).

The selective blockade of either central or peripheral opiate receptors with selective opiate antagonists produces motivational effects that are of opposite valence to those produced by the selective activation of the same receptors with opiate agonists (Bechara and van der Kooy, 1985; Bechara et al., 1987). Thus, the quaternary opiate antagonist methylnaltrexone (MN), which does not cross the blood-brain barrier (BBB) effectively (Valentino et al., 1981), produces conditioned place preferences through antagonism of endogenous opioid peptides acting on peripheral opiate receptors, the primary site mediating opiate aversive effects (Bechara and van der Kooy, 1985; Bechara et al., 1987). Recause MN acts at a site so distinct from the drugs used above, we tested the effect of TPP lesions on place preferences conditioned by MN. Two groups of drug and experiment naive rats were used for the MN place-conditioning experiment, following a 2 week recovery from sham $(n=8)$ or ibotenic acid lesions $(n=8)$ of the TPP region. All rats were place conditioned with $\mathrm{MN}(1 \mathrm{mg} / \mathrm{kg}$, i.p.).

Effects of TPP lesions on retention versus acquisition of conditioned morphine place preferences. This experiment was designed to determine whether the motivational deficits observed in TPP lesioned rats could be dissociated from other putative deficits involving the basic mechanisms of learning and memory. Through associative learning (i.e., classical conditioning), an initially weak or ineffective conditioned stimulus (CS) acquires a novel motivational significance after it has been paired with a strong unconditioned stimulus (US). After an animal has been conditioned it behaves as if the CS predicts the US. Thus, if the motivational effects of a drug (US) are repeatedly paired with a distinct place (CS) (as is the case in place conditioning), then the drug-paired environmental stimuli acquire new motivational properties in that they become capable of eliciting behavioral responses reflecting the motivational properties of the drug itself. From this analysis it is clcar that there are several possible mechanisms, other than disrupting the motivational processes underlying the US itself, by which TPP lesions could block opiate place conditioning. First, TPP lesions may cause a nonspecific interference with mechanisms underlying the learning of all CSUS associations. Second, a disruption of the neural processes mediating the CS effects themselves would also prevent the learning of a CS-US association. The experiments described above examined TPP lesion effects on the place preferences produced by drugs other than opiates, thus testing the possibility of nonspecific deficits in processing the CS or in the learning mechanisms underlying the acquisition of all conditioned place preferences. Third, the mechanisms by which the memory of the CS-US association is retained might be interrupted by TPP lesions. In order to test if TPP lesions produce a memory deficit, we place conditioned rats with morphine prior to lesioning the TPP and then tested them after the lesions for their ability to retain the previously acquired preference for places paired with morphine. Finally, after a series of extinction trials, we examined the ability of the same lesioned rats to reacquire the morphine-conditioned place preference after only a few additional pairings with morphine. This reacquisition experiment provides a strong test of our hypothesis that TPP lesions disrupt a US neural pathway mediating the positive motivational impact of opiates.

Two separate groups of drug and experiment naive rats were place conditioned with morphine $(1 \mathrm{mg} / \mathrm{kg}$, s.c.). Immediately after the last training day, one group $(n=7)$ received ibotenic acid lesions of the TPP region, and another group $(n=8)$ received sham lesions. Following a 2 week recovery from surgery, all these previously place-conditioned rats were tested for the retention of morphine-conditioned place preference. Following the testing for place conditioning, both sham and lesion groups underwent a total of 8 extinction trials. Each uninjected rat was allowed half an hour to freely explore the environment previously paired with morphine and half an hour to freely explore the environment previously paired with saline vehicle. These extinction trials alternated for a total of 4 drug-paired environment extinction and 4 vehicle-paired environment extinction trials spread over 2 days. On the third day, the sham and lesion groups were retested for any evidence of place preferences. Following the extinction trials and testing, both the sham and lesion groups underwent 2 morphine pairings $(1 \mathrm{mg} / \mathrm{kg}$, s.c.) in the environment previously paired with morphine, and on 2 alternate days they were paired with the saline vehicle in the environments previously associated with these vehicle injections. On the day following the last retraining day, these reacquisition sham and lesion groups were tested for evidence of conditioned morphine place preferences.

Anatomical characterization of the TPP region critical for psychoactive drug reward. Recent anatomical work has shown that separate TPP perikarya have ascending projections to the forebrain versus descending projections to the medulla and spinal cord (Goldsmith and van der Kooy, 1988). The distribution of TPP cell bodies with ascending versus descending projections were shown to be spatially distinct, but partially overlapping (Goldsmith and van der Kooy, 1988). One question that arises in characterizing the behavioral deficits caused by TPP lesions is whether the ibotenic acid lesions have primarily interrupted an ascending or a descending flow of information from the TPP.

Only rats with histologically verified lesions destroying a significant portion of the TPP bilaterally were included in the behavioral data analyses. However, we then subdivided the TPP lesioned rats into animals demonstrating complete blockade of the place preferences produced by morphine or amphetamine (the majority of rats), animals with lesions in the TPP that showed less complctc placc-preference deficits, and the very few animals with lesions that destroyed a significant area of the TPP yet failed to show any place-preference deficits. With the aid of a camera lucida, the TPP lesion sites from all the animals included in the behavioral analyses were drawn on previously published sche- 


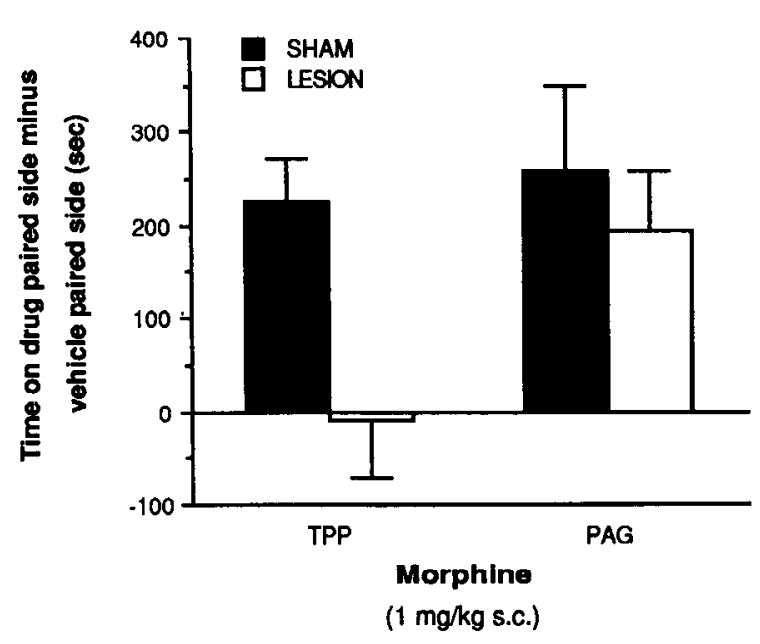

Figure 1. Effects of bilateral ibotenic acid or sham lesions of the TPP and the PAG regions on the place preferences induced by morphine in drug naive rats. Each bar represents the mean \pm SEM for $7-13$ rats.

matics of the TPP region, showing the distributions of the populations of neuronal perikarya in the TPP region with ascending versus descending projections (Goldsmith and van der Kooy, 1988).

\section{Results}

Rats with ibotenic acid lesions of the TPP region appeared grossly normal under superficial visual examination and maintained normal body weights compared with sham lesioned animals. However, rats with similar size bilateral ibotenic acid lesion in the PAG lost weight following the lesions, and a minority of these PAG lesioned rats died prior to behavioral testing. All animals included in the statistical analyses of behavioral data were histologically verified for bilateral lesions that encompassed a significant portion of the TPP region or the majority of the ventrolateral quadrant of the PAG.

The TPP extends as far rostrally as the caudal substantia nigra and retrorubral field and as far caudally (in close association with the ascending limb of the brachium conjunctivum) as the fourth cranial motor nucleus and the rostral parabrachial nucleus (Newman, 1985; Rye et al., 1987; Goldsmith and van der Kooy, 1988). Dorsally, the TPP extends as far as the cuneiform nucleus, and laterally as far as the lateral lemniscus and associated nuclei (Newman, 1985; Rye et al., 1987). The pontine tcgmental ficld and rubrospinal tract form the ventral boundaries of the TPP (Newman, 1985; Rye et al., 1987), whereas the PAG and the decussation of the brachium conjunctivum form its medial boundaries (Newman, 1985). TPP neuronal perikarya are found dorsal and ventral to, and intermingled with, the ascending fibers of the brachium conjunctivum.

The lesions and their boundaries were relatively easily defined in Nissl sections by the loss of neuronal perikarya and gliosis. Histological sections of TPP and PAG lesions at the level of the decussation of brachium conjunctivum are shown in Figure 5.

\section{Morphine-conditioned place preferences after TPP or PAG lesions}

Bilateral ibotenic acid lesions of the TPP, but not of the PAG, region abolished the positive-reinforcing effects produced by morphine ( $1 \mathrm{mg} / \mathrm{kg}$, s.c.) in drug naive rats (Fig. 1). An analysis of variance on the data from the TPP sham and lesion groups revealed a significant interaction of the TPP lesion with time

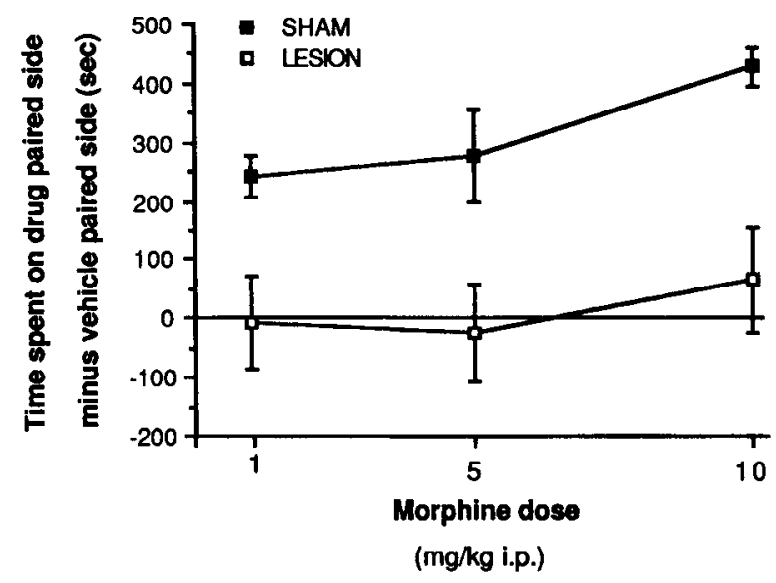

Figure 2. Effects of bilateral ibotenic acid or sham lesions of the TPP region on the conditioned place preferences produced by various doses of morphine (s.c.). Each point represents the mean \pm SEM for 5-17 rats. Each rat was trained with only one dose of morphine.

spent in the drug- versus vehicle-paired environment $\left(F_{1.19}=\right.$ $10.8, p<0.05)$. That is, the time spent in the drug- versus vehicle-paired environments depended on whether rats had sham or ibotenic acid lesions. TPP sham $[t(12)=4.7, p<0.05]$ but not TPP lesioned $[t(7)=-0.4, p>0.05]$ rats showed significant preferences for places paired with morphine. In contrast, an analysis of variance on the data from the PAG sham and lesion groups revealed a significant main effect of time spent on drugversus saline vehicle associated sides $\left(F_{1.13}=17.5, p<0.05\right)$, but no significant main effect of the lesion nor any interaction of lesion with time spent in either environment of the placeconditioning apparatus. In other words, both sham and lesioned PAG groups equally showed significant preferences for the places associated with morphine. These results demonstrate that the TPP, but not the PAG, region is critical for morphine-conditioned place preferences in drug naive rats.

\section{Dose-response analysis of morphine-conditioned place preferences after TPP lesions}

Over an order of magnitude of doses, morphine produced conditioned place preferences in rats with sham but not ibotenic acid lesion of the TPP region (Fig. 2). A 3-way analysis of variance on the TPP sham and lesion groups conditioned with different doses of morphinc revcalcd a significant interaction of lesion with time spent in the drug- versus saline vehicle-paired environments $\left(F_{1,56}=32.0, p<0.05\right)$. TPP sham, but not TPP lesioned, rats spent significantly more time on the side paired with morphine than on the side paired with saline vehicle. There was no significant 3-way interaction of dose with lesion and with time spent on drug- versus vehicle-paired side. Nevertheless, a direct comparison of the place preferences produced by 1 and $10 \mathrm{mg} / \mathrm{kg}$ morphine in the sham groups revealed larger preferences at $10 \mathrm{mg} / \mathrm{kg}[t(24)=3.5, p<0.05]$.

\section{Place preferences conditioned by amphetamine and methylnaltrexone after TPP lesions}

TPP lesions blocked amphetamine ( $1 \mathrm{mg} / \mathrm{kg}$, s.c.) conditioned place preferences (Fig. 3, left). An analysis of variance on the data from the sham amphetamine and lesion amphetamine groups revealed a significant interaction between time spent on drug- versus saline-paired sides and the lesion $\left(F_{1,14}=4.9, p<\right.$ 


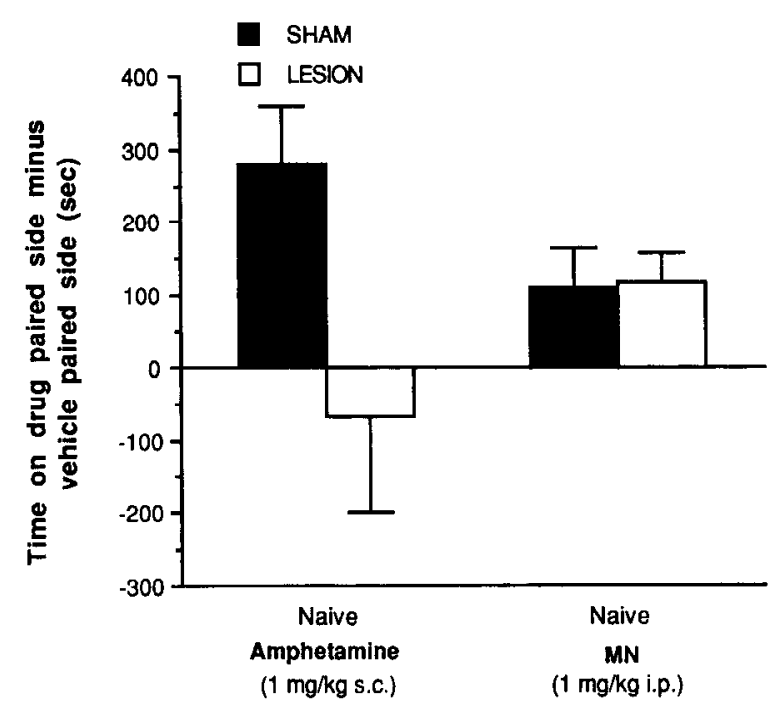

Figure 3. Effects of bilateral ibotenic acid or sham TPP lesions on the conditioned place preferences produced by amphetamine (left) and MN (right) in naive rats. Bars represent means \pm SEM for 8 rats.

$0.05)$. Sham $[t(7)=3.4, p<0.05]$, but not lesioned $[t(7)=0.5$, $p>0.05]$, rats showed significant preferences for places paired with amphetamine.

The rewarding properties of $\mathrm{MN}$ in the place-conditioning paradigm, thought to be related to the antagonism of the peripheral opioid aversive system (Bechara and van der Kooy, 1985; Bechara et al., 1987), were not blocked by TPP lesions (Fig. 3, right). An analysis of variance on the data from the sham $\mathrm{MN}$ and lesion MN groups revealed only a significant main effect of time spent on drug- versus saline vehicle-paired sides $\left(F_{1,14}=11.6, p<0.05\right)$. There was no significant main effect of lesion, nor any significant interaction. Both sham and ibotenic acid lesioned rats showed preferences for places paired with MN over places paired with the saline vehicle.

\section{Effects of TPP lesions on retention versus acquisition of conditioned morphine place preferences}

The TPP region proved critical for the acquisition, but not the retention, of a morphine-conditioned place preference (Fig. 4). Rats were conditioned with morphine in the place-preference paradigm and then received bilateral sham or ibotenic acid lesions of the TPP. Testing for retention of the place conditioning following the sham or TPP lesions revealed a significant main effect of time in drug-versus saline vehicle-paired environments $\left(F_{1,13}=31.0, p<0.05\right)$, but no significant main effect of lesion nor any interaction of lesion with time spent in each compartment of the place-conditioning apparatus. Thus, both sham and TPP lesioned rats showed significant retention of preferences for places paired with morphine prior to surgery (Fig. 4, left).

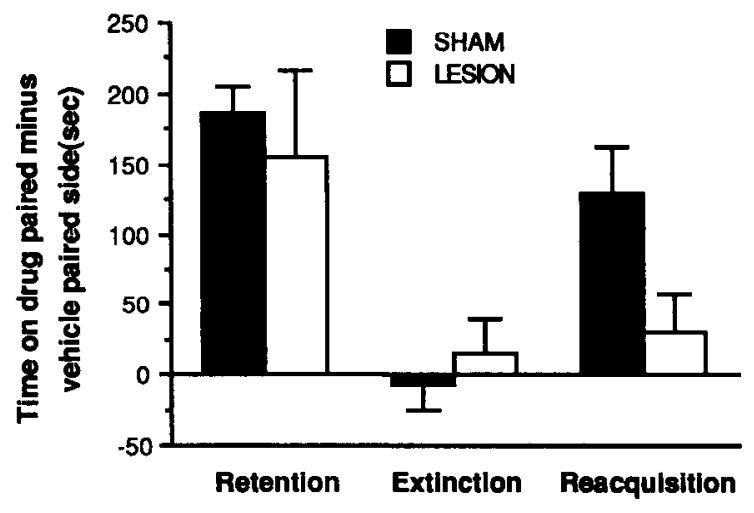

Figure 4. Effects of bilateral ibotenic acid or sham TPP lesions on the retention of a morphine-conditioned place preference acquired prior to the lesions (left), on the extinction of these preferences (middle), and on the ability of these same rats to reacquire conditioned place preferences after 2 additional morphine pairings (right). Bars represent means \pm SEM for 7-8 rats.

After extinction, neither the sham nor lesion rats showed significant preferences for the drug or saline vehicle-paired sides of the test box (Fig. 4, middle). However, testing for the reacquisition of the place conditioning in the sham or TPP lesioned animals revealed a significant interaction of lesion with time spent in drug- versus saline vehicle-paired environments $\left(F_{1,13}\right.$ $=5.0, p<0.05)$. Sham $[t(7)=3.8, p<0.05]$, but not lesioned $[t(6)=1.1, p>0.05]$, rats showed significant preferences for places paired with 2 injections of morphine during the reacquisition phase of the experiment (Fig. 4, right). In sum, lesions of the TPP region produce a deficit in the acquisition and reacquisition, but not the retention, of a morphine-conditioned place preference. This experiment strongly supports the idea that TPP lesions block the unconditioned positive-reinforcing effects of morphine in nonopiate-dependent rats but do not block the action or extinction of conditioned stimuli that had been paired with morphine prior to the lesions.

\section{Anatomical characterization of the TPP region critical for psychoactive drug reward}

The motivational deficits produced by TPP lesions in the present experiments were specific to the TPP region and were not seen after PAG lesions (Fig. 5). Furthermore, 1 rat with ibotenic acid lesions directly dorsal to the TPP (in the cuneiform nucleus), and 3 rats with lesions that were far dorsal to the TPP (infringing on the superior and inferior colliculi), also failed to demonstrate any motivational deficits. These animals were not included in the TPP groups for behavioral analyses. All rats with ibotenic acid lesions that destroyed a significant portion of the TPP bilaterally were included in the bchavioral analyscs. However,

Figure 5. A, Schematics of the average diameters of clusters of ibotenic acid lesions of the TPP that were completely effective (solid lines), partially effective (shaded areas) or noneffective (dashed lines) in blocking the effects of morphine and amphetamine in the place-preference tests. Photomicrographs of Nissl-stained frontal sections through similar rostrocaudal levels of the pons show bilateral ibotenic acid lesions (arrows) of the TPP that were completely effective $(B)$ or partially effective $(C)$ in producing the motivational deficits. After bilateral ibotenic acid lesions of the PAG, a photomicrograph of a Nissl-stained section $(D)$ shows shrinkage of the ventrolateral portions (arrows) of the PAG region due to the loss of neuronal perikarya. The lesions showed gross bilateral symmetry, but the schematics of the TPP lesions were drawn only unilaterally $(A)$. These schematics were compared with the distributions of cells in the TPP and surrounding region with ipsilateral ascending versus descending projections. 
A
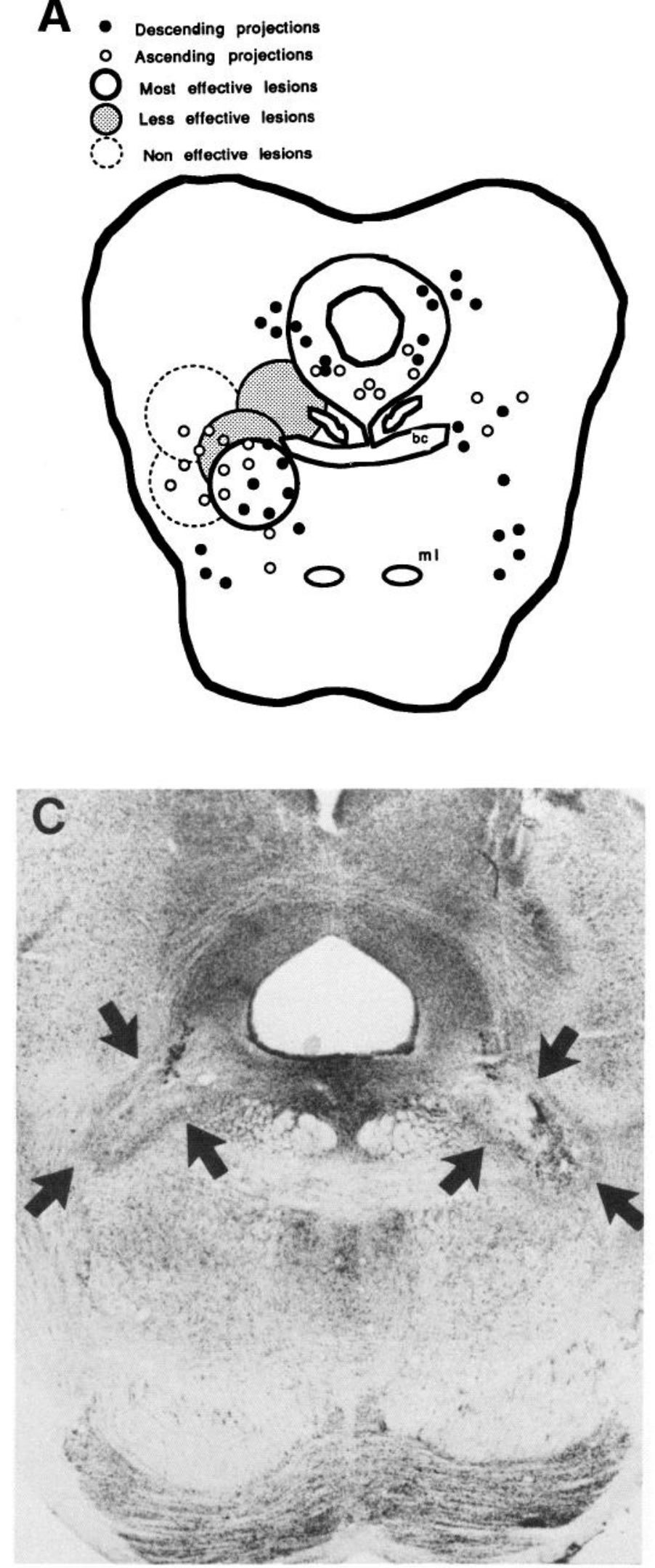

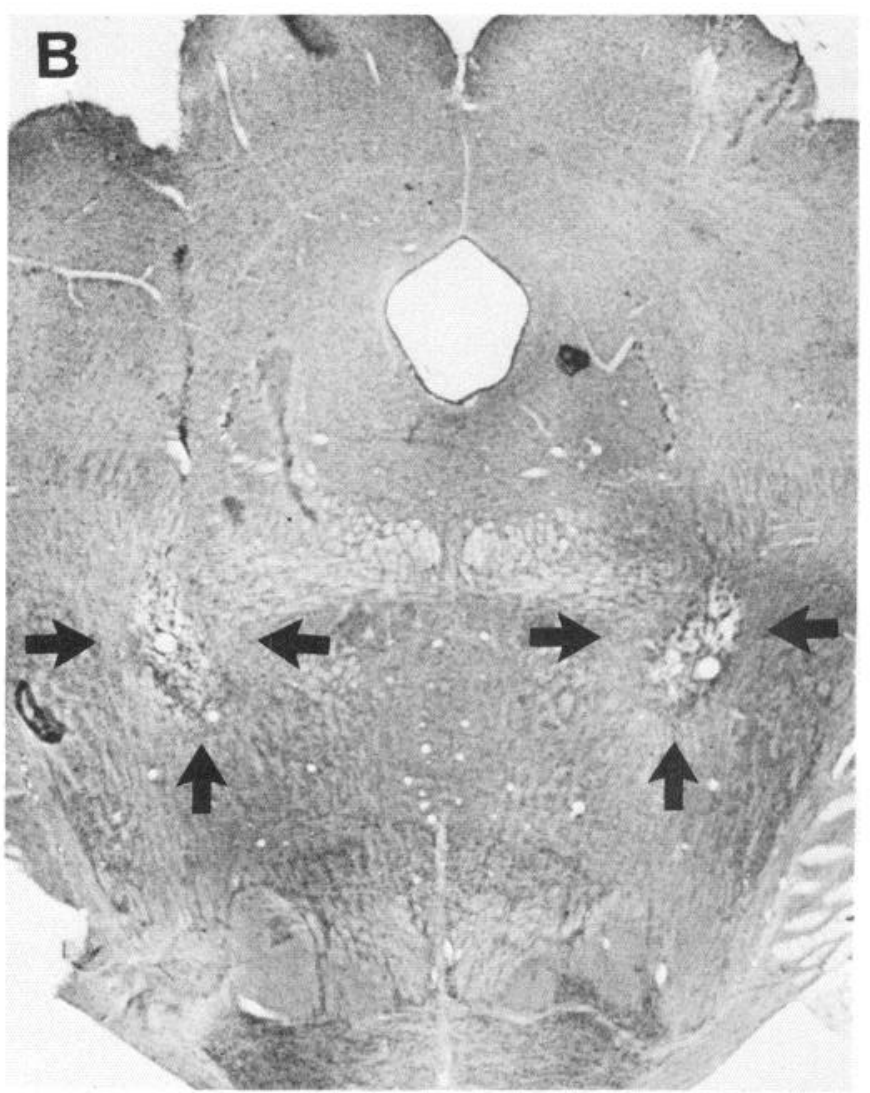

D

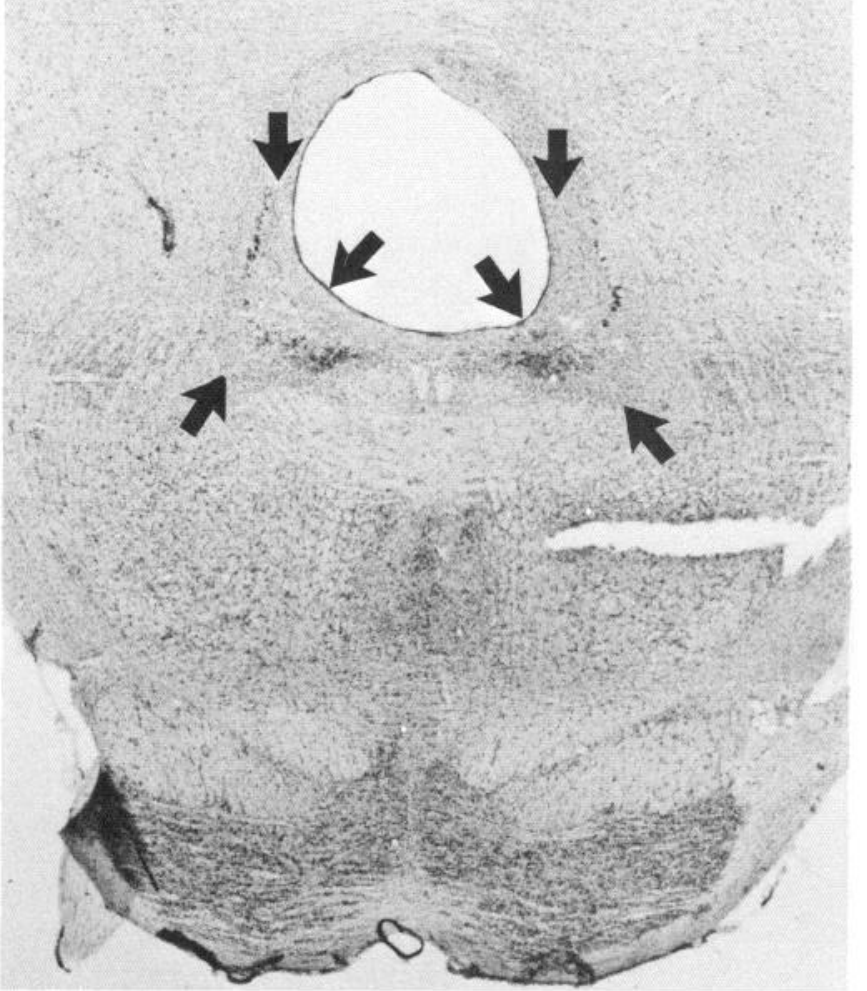

Solid dots (bilaterally) represent neuronal perikarya retrogradely labeled from the spinal cord ipsilateral to the schematized lesions, and open dots (bilaterally) represent neurons retrogradely labeled from the ipsilateral thalamus. The completely effective lesions appear to destroy a greater percentage of TPP cells with descending than with ascending projections. This is in contrast to the noneffective lesions, which appear to spare the TPP cells with descending projections and primarily destroy the cells with ascending projections. Distributions of labeled neuronal perikarya were taken from Goldsmith and van der Kooy (1988). 
within the collection of TPP lesioned animals there was some variation in the individual lesions, which appeared to correspond to the degree of motivational deficits and, to a certain extent, to the origin of various efferent projections from the TPP. Figure $5 A$ shows the average diameters of various clusters of TPP lesions that were defined on the basis of their behavioral effects. Specifically, the very few TPP lesioned rats that failed to show any behavioral deficits in the morphine or amphetamine place-preference tests proved to have lesions that fell more laterally (either dorsolaterally or ventrolaterally) in the TPP region. In contrast, rats with TPP lesions that included the more ventromedial areas (and thus ventral to the decussation of the brachium conjunctivum) tended to show complete blockade in the same place-preference tests. However, several rats with TPP lesions that destroyed the medial and dorsomedial regions of the TPP (at the level or dorsal to the decussation of the brachium conjunctivum) appeared to show somewhat less complete deficits in the morphine or amphetamine place-preference tests. Comparing these variations in lesion sites to the distribution of TPP perikarya with descending versus ascending projections (Fig. $5 A$ ), we find that the ventromedial lesion sites that resulted in the most complete blockade of morphine and amphetamine motivational effects overlapped a larger percentage of the TPP neurons with descending than with ascending projections. Nevertheless, these same maximally effective lesions also destroyed a significant population of the TPP cells with ascending projections, so that no absolute conclusion can be drawn concerning the directionality of the TPP efferents underlying the behavioral deficits. However, it is important to note that the lesion sites that spared most of the TPP cells with descending projections and destroyed primarily the TPP ncurons with ascending projections produced no or only partial behavioral deficits.

\section{Discussion}

This series of experiments has revealed that the TPP region serves as a critical brain-stem substrate in the system underlying the unconditioned positive-reinforcing properties of morphine as measured in the place-conditioning paradigm. The fact that TPP lesions also blocked the positive-reinforcing effects of amphetamine suggests that the TPP region may serve as a nodal brain-stem substrate for the rewarding properties of many psychoactive drugs. The failure of TPP lesions to block the conditioned taste aversions produced by morphine and amphetamine (Bechara and van der Kooy, 1986) emphasize the motivational specificity of the deficits. However, before accepting that TPP lesions cause a specific motivational deficit, other explanations of the behavioral changes must be considered.

First, TPP lesions may primarily affect state-dependent learning. It could be argued that the rewarding properties of the drugs tested in TPP lesioned animals were still intact; however, these reinforcing properties are no longer expressed unless animals are tested in the "drugged" state, and even then TPP lesions may block the discrimination of the "drugged" state. Standing against such a possibility is evidence that state-dependent learning plays no role in opiate preference conditioning procedures like the ones used here (Mucha et al., 1982; Mucha and Iverson, 1984; Carr et al., 1989). Furthermore, TPP lesioned animals showed normal preferences for the MN-paired side when tested in the absence of $\mathrm{MN}$, suggesting that a drug state is not necessary for the expression of place preferences in lesioned ani- mals. Finally, a direct assessment of the discriminative or statedependent properties of morphine showed that TPP lesions had no effect on these properties (Martin et al., 1987).

Second, TPP lesions may have blocked place preferences as a by-product of effects on locomotor excitation. Previous reports have indicated that the place-conditioning effects of psychoactive drugs are correlated with the amount of exploratory activity exhibited by the animals in the place-conditioning apparatus (Swerdlow and Koob, 1984). This becomes critical in light of our preliminary findings that TPP lesions also blocked the hyperactivity produced by morphine and amphetamine in the open field (Bechara and van der Kooy, 1986). One could argue that the failure of TPP lesioned animals to express preferences for places conditioned to the reinforcing effects of morphine or amphetamine resulted from a compromised locomotor exploration of the drug compartment by lesioned, but not sham, animals during conditioning. However, recent evidence shows that the development of a conditioned place preference does not depend on the amount of locomotor activity experienced in the place-conditioning apparatus (Carr et al., 1988, 1989). Indeed, the attenuation or blockade of amphetamine-induced locomotor activity during conditioning did not prevent the development and expression of amphetamine-conditioned place preferences (Di Scala et al., 1985; Carr et al., 1988). Furthermore, locomotor deficits produced by TPP lesions have no effect on the conditioned place preferences produced by $\mathrm{MN}$.

Thus, locomotor deficits cannot explain the blockade of morphine- and amphetamine-conditioned place preferences by TPP lesions. However, the fact that TPP lesions could block both the positive-reinforcing (present results) and the hyperactivity (Bechara and van der Kooy, 1986) effects of morphine and amphetamine suggests that the appetitive and the motor-activating properties of these psychoactive drugs may be subserved by a common neural system. It has been suggested that complex motor patterns, involving the sequential performance of a variety of movements that constitute approach behavior and exploration, are organized in some "preformed" state within the brain stem (Glickman and Schif,, 1967). Indeed, it has been postulated that reinforcement evolved with and is isomorphic with the activation of the neural pathways underlying species typical approach behaviors (Glickman and Schiff, 1967). Our findings that a single brain-stem lesion may disrupt both the positive-reinforcing and the locomotor excitatory effects of morphine and amphetamine lends some evidence to the Glickman and Schiff (1967) biological theory of reinforcement. We suggest that the activation of this appetitive locomotor system in the TPP, through excitation generated by rewarding drug stimuli acting at more rostral medial forebrain bundle sites, constitutes a necessary condition for these drugs to have positive incentive motivational impact in non-drug-dependent animals. However, the ability of TPP lesions to block the positive-reinforcing properties of some drug reinforcers (morphine and amphetamine), but not others (MN and morphine in opiate-dependent subjects, Bechara and van der Kooy, 1987, 1988), suggests that there may be multiple parallel reinforcement systems in the brain.

Our results have also demonstrated that the behavioral deficits produced by TPP lesions are not a by-product of nonspecific interference with fundamental mechanisms of learning and memory. First, the normal place conditioning seen with MN and with morphine in opiate-dependent rats (Bechara and van der Kooy, 1987, 1988) demonstrate that TPP lesioned rats are still capable of acquiring conditioned place preferences. Second, 
the retention experiment revealed that TPP lesioned rats are capable of remembering the conditioned reinforcing properties of places associated with morphine if the conditioning preceded the lesions. Interestingly, after the extinction of the place preferences in these rats, sham but not TPP lesioned rats reacquired conditioned preferences for places paired with morphine. These results strongly suggest that TPP lesions disrupt the unconditioned rcinforcing effects of morphine itself, but not the conditioned reinforcing effects of stimuli previously associated with morphine. Thus, the conditioned stimulus processing pathway, as well as the anatomical site(s) mediating the CS-US association and the memory of this association, all remain to be identified.

\section{Specifying the critical TPP neurons}

IrImunocytochemical procedures have established that many cells within the TPP in the rat are cholinergic (Newman, 1985; Garcia-Rill, 1986; Rye et al., 1987). Moreover, the distribution of cholinergic TPP cells overlaps the distribution of sites producing locomotion after electrical stimulation in both the cat and the rat (Garcia-Rill, 1986). However, our maximally effective lesions for producing motivational deficits extended further medially and ventrally than the distribution of the largest concentration of cholinergic cells in the TPP (Rye et al., 1987, 1988; Goldsmith and van der Kooy, 1988). Lesion sites that extended laterally and thus overlapped the distribution of the largest concentration of cholinergic TPP neurons (Rye et al., 1987, 1988; Goldsmith and van der Kooy, 1988) did not produce motivational deficits. Thus, the critical lesions defined a ventromedial area of the TPP that corresponds to a population of mostly noncholinergic neuronal perikarya with axons descending to the ventromedial medulla and spinal cord (Rye et al., 1987, 1988; Goldsmith and van der Kooy, 1988). This area contrasts with the lateral portion of the TPP (especially the dorsolateral portion) that contains the majority of the cholinergic neurons, which have diffuse ascending projections to the thalamus and the forebrain (Sofroniew et al., 1985; Goldsmith and van der Kooy, 1988).

Rye et al. (1987, 1988) have recently termed the mostly noncholinergic neurons in the path of descending basal ganglia input as the midbrain extrapyramidal area. They separated the midbrain extrapyramidal area from the laterally adjacent TPP, which was defined by the dense concentration of medium and largesized cholinergic neurons, and suggested that the midbrain extrapyramidal area was most homologous to the mesencephalic locomotor region (Rye et al., 1987, 1988).

Rye et al. (1987, 1988) have placed the midbrain extrapyramidal arca dorsal to the decussation of the brachium conjunctivum. Our lesions, which destroy this region, at least partially block the positive-reinforcing effects of morphine and amphetamine. However, it is clear that our maximally effective lesions [as well as the perikarya with descending projections (Goldsmith and van der Kooy, 1988)] also extend ventral to the decussation of the brachium conjunctivum. Furthermore, the extrapyramidal inputs to this region, which presumably dcfine the midbrain extrapyramidal area, also extend ventral to the decussation of the brachium conjunctivum, and in the case of the substantia nigra pars reticulata the projections are denser ventromedially than dorsomedially with respect to the decussation of the brachium conjunctivum (Beckstead et al., 1979). Thus, we propose that the critical area for psychoactive drug reward is the ventromedial TPP, rather than the midbrain extrapyramidal area as defined by Rye et al. $(1987,1988)$.

\section{The TPP as a critical output of the brain reward circuitry}

Microinjection studies have revealed that the receptor sites where opiates and stimulants act to produce positive-reinforcing effects are in the limbic forebrain and midbrain (Phillips and LePiane, 1980; van der Kooy et al., 1982; Wise and Bozarth, 1982; Vaccarino et al., 1985; Carr and White, 1986). Regions that receive neuronal inputs from these positive-reward sites have been proposed as critical reward centers. Indeed, there is substantial evidence that the dopamine neurons of the ventral tegmental area can serve as a nexus point for psychoactive drug reward (Wise and Bozarth, 1987; Wise, 1988), although the validity of this conclusion specifically for opiate reward has been challenged by other investigators (Ettenberg et al., 1982; Mackey and van der Kooy, 1985). Furthermore, previous lesion studics have pointed to the importance of the neuronal cell bodies within the nucleus accumbens (Zito et al., 1985) and the ventral pallidum (substantia innominata) (Hubner and Koob, 1987; Koob and Swerdlow, 1989) in opiate and stimulant rewards. In particular, the disruption of cocaine and heroin self-administration by lesions of the nucleus accumbens was attributed to the destruction of the target of the dopaminergic projections from the ventral tegmental area (Zito et al., 1985). Similarly, the disruption of psychoactive drug reward by ventral pallidal lesions was attributed to the destruction of the target of accumbens projections (Swerdlow et al., 1984; Hubner and Koob, 1987; Koob and Swerdlow, 1989). Thus, it has been hypothesized that psychoactive drugs elicit their positive-reinforcing effects via neural excitation of a ventral tegmental area-accumbens-ventral pallidal system (Koob and Bloom, 1988).

Anatomical evidence indicates that the TPP region of the midbrain and pons receives neuronal inputs from all of these structures identified as positive reward sites, via direct monosynaptic or indirect multisynaptic pathways (Nauta et al., 1978; Saper et al., 1979; Swanson, 1982; Swanson et al., 1984, 1987). Furthermore, it has been suggested that the putative brain sites identified as critical for drug reward appear to form a chain of neuronal structures linked in scrics to the TPP region of the brain stem (Koob and Bloom, 1988). Electrophysiological studies indicate that the reward information generated by electrical brain stimulation at forebrain sites are carried through descending pathways of the medial forebrain bundle to the midbrain (Bielajew and Shizgal, 1986). The TPP itself has low levels of opiate receptors (Herkenham and Pert, 1982; Mansour et al., 1986), and thus we propose that the TPP is the neuronal link in an incentive reward system after the receptor-bearing neurons. Given our results that TPP lesions block the positivereinforcing effects of amphetamine as well as of morphine, we suggest that the TPP region serves as a nodal point for the reward generated by opiates and stimulants acting at various sites in the forebrain and exiting the limbic system in the TPP region of the brain stem. Furthermore, we have preliminary results showing that TPP lesions block the place preferences produced by food in non-food-deprived, but not in food-deprived, animals (Bechara and van der Kooy, 1988). Thus, it remains to be seen whether the TPP region can similarly serve as a nexus point in the relay of reward information from natural reinforcers such as food, water, and sex.

The identification of the IPP as a critical site in morphine and amphetamine reward provides an anatomical substrate for studying the translation of rewarding drug stimuli (acting at "upstream" limbic regions) into action and drug-seeking be- 
havior. In addition to its anatomical connections with all the putative reward centers of the brain (i.e., nucleus accumbens, ventral pallidum, lateral hypothalamus, ventral tegmental area), the TPP is also in a position to influence a variety of somatomotor responses, since it projects directly to widespread parts of the brain-stem reticular formation (Moon Edley and Graybiel, 1983), the thalamus (Sofroniew et al., 1985; Hallanger et al., 1987), the spinal cord (Swanson et al., 1984; Goldsmith and van der Kooy, 1988; Rye et al., 1988), and the basal ganglia and associated structures (Saper and Loewy, 1982; Garcia-Rill, 1983; Jackson and Crossman, 1983; Moon Edley and Graybiel, 1983; Steeves and Jordan, 1984). Furthermore, the TPP region appears to overlap the mesencephalic locomotor region, a region that facilitates locomotion when electrically stimulated in the decerebrate rat (Skinner and Garcia-Rill, 1984). Indeed, it has been shown that the injection of the local anesthetic procaine into the TPP blocks forebrain-elicited increases in locomotion (Mogenson and $\mathrm{Wu}, 1988$ ). Thus, in addition to its critical role in reward functions, the TPP region appears to be involved in locomotor behaviors (Garcia-Rill, 1986). Therefore, we suggest that the neural information generated by psychoactive drugs acting on "upstream" reward sites of the brain, and descending through the medial forebrain bundle, exits the limbic system in the TPP region of the brain stem where reward can influence appetitive and drug-seeking behaviors.

\section{Heferences}

Atweh, S. F., and M. J. Kuhar (1977a) Autoradiographic localization of opiate receptors in rat brain. II. The brainstem. Brain Res. 129: $1-12$.

Atweh, S. F., and M. J. Kuhar (1977b) Autoradiographic localization of opiate receptors in rat brain. III. The telencephalon. Brain Res. 134: 393-405.

Bechara, A., and D. van der Kooy (1985) Opposite motivational effects of endogenous opioids in brain and periphery. Nature 314: 533-534.

Bechara, A., and D. van der Kooy (1986) Lesion of a brainstem output of the limbic system abolishes the rewarding effects of psychoactive drugs. Soc. Neurosci. Abstr. 12: 936.

Bechara, A., and D. van der Kooy (1987) Separation of morphine's incentive motivational from its escape from withdrawal properties. Soc. Neurosci. Abstr. 13: 1547.

Bechara, A., and D. van der Kooy (1988) The incentive motivational properties of food and opiates are mediated by a common brainstem substrate. Soc. Neurosci. Abstr. 14: 1103.

Bechara, A., K. A. Zito, and D. van der Kooy (1987) Peripheral receptors mediate the aversive conditioning effects of morphine in the rat. Pharmacol. Biochem. Behav. 28: 219-225.

Beckstead, R. M., V. B. Domesick, and W. J. H. Nauta (1979) Efferent connections of the substantia nigra and ventral tegmental area in the rat. Brain Res. 175: 191-217.

Bielajew, C., and P. Shizgal (1986) Evidence implicating descending fibres in self-stimulation of the medial forebrain bundle. J. Neurosci. 6: 919-929.

Boyd, E. S., and L. C. Gardner (1967) Effect of some brain lesions on intracranial self-stimulation in the rat. Am. J. Physiol. 213: 10441052.

Bozarth, M. A., and R. A. Wise (1981) Intracranial self-administration of morphine into the ventral tegmental area in rats. Life Sci. $28: 551-$ 555.

Carr, G. D., and N. W. White (1986) Anatomical dissociation of amphetamine's rewarding and aversive effects: An intra-cranial microinjection study. Psychopharmacology 39: 340-346.

Carr, G. D., A. G. Phillips, and H. C. Fibiger (1988) Independence of amphetamine reward from locomotor stimulation demonstrated by conditioned place preference. Psychopharmacology 94: 221-226.

Carr, G. D., A. G. Phillips, and H. C. Fibiger (1989) Conditioned place preference as a measure of drug reward. In Oxford Reviews in Psychopharmacology, Vol. 1, Neuropharmacological Basis of Reward,
J. M. Liebman and S. J. Cooper, eds., Oxford U. P., New York (in press).

Coyle, J. T., and R. Schwarcz (1983) The use of excitatory amino acids as selective neurotoxins. In Handbook of Chemical Neuroanatomy, Vol. 1: Methods in Chemical Neuroanatomy, A. Bjorklund and T. Hokfelt, eds., pp. 67-95, Elsevier, Amsterdam.

Di Scala, G., M. T. Martin-Iverson, A. G. Phillips, and H. C. Fibiger (1985) The effects of progabide (SL 76002) on locomotor activity and conditioned place preference induced by d-amphetamine. Eur. J. Pharmacol. 107: 271-274.

Ettenberg, A., H. O. Petit, F. E. Bloom, and G. F. Koob (1982) Heroin and cocaine intravenous self administration in rats: Mediation by separate neural systems. Psychopharmacology 78: 204-209.

Garcia-Rill, E. (1983) Connections of the mesencephalic locomotor region (MLR). III. Intracellular recordings. Brain Res. 10: 73-81.

Garcia-Rill, E. (1986) The basal ganglia and the locomotor regions. Brain Res. Rev. 11: 47-63.

Glickman, S. E., and B. B. Schiff (1967) A biological theory of reinforcement. Psychol. Rev. 74: 81-109.

Goeders, N. E., J. D. Lane, and J. E. Smith (1984) Self administration of methionine enkephalin into the nucleus accumbens. Pharmacol. Biochem. Behav. 20: 451-455.

Goldsmith, M., and D. van der Kooy (1988) Separate non cholinergic descending projections and cholinergic ascending projections from the nucleus tegmenti pedunculopontinus. Brain Res. 445: 386-391.

Hallanger, A. E., A. I. Levey, H. J. Lee, D. B. Rye, and B. H. Wainer (1987) The origins of cholinergic and other subcortical afferents to the thalamus in the rat. J. Comp. Neurol. 262: 105-124.

Heinrichs, S. C., and J. L. Martinez, Jr. (1986) Modification of place preference conditioning in mice by systematically administered [leu] enkephalin. Behav. Brain Res. 22: 249-255.

Herkenham, M., and C. B. Pert (1982) Light microscopic localization of brain opiate receptors: A general autoradiographic method which preserves tissue quality. J. Neurosci. 2: 1129-1141.

Hoebel, B. G., L. Hernandez, S. McLean, B. Stanley, E. Aulissi, P. Glimcher, and D. Margolin (1982) Cathecolamine, enkephalin, and neurotensin in feeding and reward. In The Neural Basis of Feeding and Reward, B. G. Hoebel and D. Novin, eds., Haer Institute, Brunswick, ME.

Hubner, C. B., and G. F. Koob (1987) Ventral pallidal lesions produce decreases in cocaine and heroin self administration in the rat. Soc. Neurosci. Abstr. 13: 1717.

Huston, J. P., and A. A. Borbely (1973) Operant conditioning in forebrain ablated rats by use of rewarding hypothalamic stimulation. Brain Res. 50: 467-472.

Jackson, A., and A. Crossman (1983) Nucleus tegmenti pedunculopontinus: Efferent connections with special reference to the basal ganglia studies in the rat by anterograde and retrograde transport of horseradish peroxidase. Neuroscience 10:725-765.

Koob, G. F., and F. E. Bloom (1988) Cellular and molecular mechanisms of drug dependence. Science 242: 715-723.

Koob, G. F., and N. R. Swerdlow (1989) The functional output of the mesolimbic dopamine system. Ann. NY Acad. Sci. (in press).

Mackey, W. B., and D. van der Kooy (1985) Neuroleptics block the positive reinforcing effects of amphetamine but not of morphine as measured by place conditioning. Pharmacol. Biochem. Behav. 22: 101-106.

MacLean, P. D. (1949) Psychosomatic disease and the "visceral brain." Psychosom. Med. 11: 338-353.

Mansour, A., M. E. Lewis, H. Khachaturian, H. Akil, and S. J. Watson (1986) Pharmacological and anatomical evidence of selective mu, delta, and kappa opioid receptor binding in rat brain. Brain Res. 399: 69-79.

Martin, G. M., A. Bechara, and D. van der Kooy (1987) Dissociation of morphine's discriminative stimulus properties from its motivational properties. Soc. Neurosci. Abstr. 13: 1546.

Mogenson, G. J., and M. Wu (1988) Differential effects on locomotor activity of injections of procaine into mediodorsal thalamus and pedunculopontine nucleus. Brain Res. Bull. 20: 241-246.

Moon Edley, S., and A. M. Graybiel (1983) The afferent and efferent connections of the feline nucleus tegmenti pedunculopontinus, pars compacta. J. Comp. Neurol. 217: 187-215.

Mucha, R. F., and S. D. Iverson (1984) Reinforcing properties of morphine and naloxone revealed by conditioned place preference: A procedural examination. Psychopharmacology 82: 241-247. 
Mucha, R. F., D. van der Kooy, M. O'Shaughnessy, and P. Bucenieks (1982) Drug reinforcement studies by the use of place conditioning in rat. Brain Res. 243: 91-105.

Nauta, W. J. H. (1958) Hippocampal projections and related neural pathways to the midbrain in the cat. Brain $81: 319-341$.

Nauta, W. J. H., G. P. Smith, V. B. Domesick, and R. L. M. Faull (1978) Efferent connections and nigral afferents of the nucleus accumbens septi in the rat. Neuroscience 3: 385-401.

Newman, D. B. (1985) Distinguishing rat brainstem reticulospinal nuclei by neuronal morphology. II. Pontine and mesencephalic nuclei. J. Himforsch. 26: 385-418.

Nieuwenhuys, R., L. M. G. Geeraedts, and J. G. Veening (1982) The medial forebrain bundle of the rat. I. General introduction. J. Comp. Neurol. 206: 49-81.

Olds, M. E. (1979) Hypothalamic substrates for the positive reinforcing properties of morphine in the rat. Brain Res. 168: 351-360.

Olds, M. E. (1982) Reinforcing effects of morphine in the nucleus accumbens. Brain Res. 237: 429-440.

Olds, J., and M. Olds (1965) Drives, rewards, and the brain. In New Directions in Psychology, Vol, 2, F. Barron and W. C. Dement, eds., pp. 327-410, Holt, Rinehart, and Winston, New York.

Olds, M. E., and J. Olds (1969) Effects of lesions in medial forebrain bundle on self-stimulation behavior. Am. J. Physiol. 217: 1253-1264.

Olds, M. E., and K. N. Williams (1980) Self-administration of D-alamet-enkephelinamide at hypothalamic self-stimulation sites. Brain Res. 194: 155-170.

Papez, J. W. (1937) A proposed mechanism of emotion. Arch. Neurol. Psychiatry 38: 725-743.

Paxinos, G., and C. Watson (1982) The Rat Brain in Stereotaxic Coordinates, Academic, New York.

Phillips, A. G., and F. G. LePiane (1980) Reinforcing effects of morphine microinjections into the ventral tegmental area. Pharmacol. Biochem. Behav. 12: 965-968.

Phillips, A. G., and F. G. LePiane (1982) Reward produced by microinjection of (D-Ala), Met-enkephalinamide into the ventral tegmental area. Behav. Brain Res. 5: 225-229.

Rolls, E. T. (1975) The neural basis of brain-stimulation reward. In The Brain and Reward, pp. 15-70, Pergamon, Oxford.

Rye, D., C. B. Saper, H. J. Lee, and B. H. Wainer (1987) Pedunculopontine tegmental nucleus of the rat: Cytoarchitecture, cytochemistry, and some extrapyramidal connections of the mesopontine tegmentum. J. Comp. Neurol. 259: 483-528.

Rye, D., H. J. Lee, C. B. Saper, and B. H. Wainer (1988) Medullary and spinal efferents of the pedunculopontine tegmental nucleus and adjacent mesopontine tegmentum in the rat. J. Comp. Neurol. 269: $315-341$.

Saper, C. B., and A. D. Loewy (1982) Projections of the pedunculopontine tegmental nucleus in the rat: Evidence for additional extrapyramidal circuitry. Brain Res. 252: 367-372.

Saper, C. B., L. W. Swanson, and W. M. Cowan (1979) An autoradiographic study of the efferent connections of the lateral hypothalamic area in the rat. J. Comp. Neurol. 183: 689-706.

Scoles, M. T., and S. Siegel (1986) A potential role of saline trials in morphine induced place preference conditioning. Pharmacol. Biochem. Behav. 25: 1169-1 173.

Shizgal, P., C. Bielajew, D. Corbett, R. Skelton, and J. Yeomans (1980) Behavioral methods for inferring anatomical linkage between rewarding brain stimulation sites. J. Comp. Physiol. Psychol. 94: 227237.

Skinner, R. D., and E. Garcia-Rill (1984) The mesencephalic locomotor region (MLR) in the rat. Brain Res. 323: 385-389.

Sofroniew, M. V., J. V. Priestly, A. Consolazione, F. Eckenstein, and A. C. Cuello (1985) Cholinergic projections from the midbrain and pons to the thalamus in the rat, identified by combined retrograde tracing and choline acetyltransferase immunohistochemistry. Brain Res. 329: 313-323.

Stceves, J. D., and L. M. Jordan (1984) Autoradiographic demon- stration of the projections from the mesencephalic locomotor region. Brain Res. 307: 263-276.

Stewart, J., H. de Wit, and R. Eikelboom (1984) Role of unconditioned and conditioned drug effects in the self-administration of opiates and stimulants. Psychol. Rev. 91: 251-268.

Swanson, L. W. (1982) The projections of the ventral tegmental area and adjacent regions: A combined fluorescent retrograde tracer and immunofluorescence study in the rat. Brain Res. Bull. 9: 321-353.

Swanson, L. W. (1983) The hippocampus and the concept of the limbic system. In Neurobiology of the Hippocampus, W. Seifert, ed., pp. 119, Academic, New York.

Swanson, L. W., and H. G. J. M. Kuypers (1980) The paraventricular nucleus of the hypothalamus: Cytoarchitectonic subdivisions and organization of projections to the pituitary, dorsal vagal complex, and spinal cord as demonstrated by retrograde fluorescence double-labelling methods. J. Comp. Neurol. 194: 555-570.

Swanson, L. W., G. J. Mogenson, C. R. Gerfen, and P. Robinson (1984) Evidence for a projection from the lateral preoptic area and substantia innominata to the "mesencephalic locomotor region" in the rat. Brain Res. 295:161-178.

Swanson, L. W., G. J. Mogenson, R. B. Simerly, and M. Wu (1987) Anatomical and electrophysiological evidence for a projection from the medial preoptic area to the "mesencephalic and subthalamic locomotor regions" in the rat. Brain Res. 405: 108-122.

Swerdlow, N. R., and G. F. Koob (1984) Restrained rats learn amphetamine-conditioned locomotion, but not place preference. Psychopharmacology 84: 163-166.

Swerdlow, N. R., L. W. Swanson, and G. F. Koob (1984) Electrolytic lesions of the substantia innominata and lateral preoptic area attenuate the "supersensitive" locomotor response to apomorphine from denervation of the nucleus accumbens. Brain Res. 306: 141-148.

Vaccarino, F. J., F. E. Bloom, and G. F. Koob (1985) Blockade of nucleus accumbens opiate receptors attenuates intravenous heroin reward in the rat. Psychopharmacology 86: 37-42.

Valentino, R. J., S. Herling, J. H. Woods, F. Medzihradsky, and H. Merz (1981) Quaternary naloxone: Evidence for the central mediation of discriminative stimulus effects of narcotic agonists and antagonists. J. Pharmacol. Exp. Ther. 217: 652-659.

van der Kooy, D. (1987) Place conditioning: A simple and effective method for assessing the motivational properties of drugs. In Methods of Assessing the Reinforcing Properties of Abused Drugs, M. A. Bozarth, ed., pp. 229-240, Springer-Verlag, New York.

van der Kooy, D., R. F. Mucha, M. O'Shaughnessy, and P. Bucenieks (1982) Reinforcing effects of brain microinjections of morphine revealed by conditioned place preference. Brain Res. 243: 107-117.

Veening, J. G., L. W. Swanson, W. M. Cowan, R. Nieuwenhuys, and L. M. G. Geeraedts (1982) The medial forebrain bundle of the rat. II. An autoradiographic study of the topography of the major descending and ascending components. J. Comp. Neurol. 206: 82-108.

Wise, R. A. (1988) The neurobiology of craving: Implications for the understanding and treatment of addiction. J. Abnorm. Psychol. 97: $118-132$.

Wise, R. A., and M. A. Bozarth (1982) Action of drugs of abuse on brain reward systems: An update with specific attention to opiates. Pharmacol. Biochem. Behav. 17: 239-243.

Wise, R. A., and M. A. Bozarth (1984) Brain reward circuitry: Four circuit elements "wired" in apparent series. Brain Res. Bull. 12: 203208.

Wise, R. A., and M. A. Bozarth (1987) A psychomotor stimulant theory of addiction. Psychol. Rev. 94: 469-492.

Yeomans, J. S. (1989) Mechanisms of brain stimulation reward. In Progress in Psychobiology and Physiological Psychology, Vol. 13, A. N. Epstein and A. Morrison, eds., Academic, London (in press).

Zito, K. A., G. Vickers, and D. C. S. Roberts (1985) Disruption of cocaine and heroin self administration following kainic acid lesions of the nucleus accumbens. Pharmacol. Biochem. Behav. 23: 10291036. 